\title{
¿Éxito táctico o fracaso estratégico? High Value Target y su aplicación a la guerra contra el narcotráfico $(2006-2012)^{\star}$
}

\author{
Tactical success or strategic failure? \\ High Value Target and its application to the War on Drugs (2006-2012)
}

\author{
Esteban Arratia Sandoval ${ }^{* *}$ \\ Academia Nacional de Estudios Políticos y Estratégicos, Santiago, Chile
}

Recibido: 30 de julio de 2015. Aprobado: 30 de septiembre de 2015.

\begin{abstract}
Resumen
El reciente escape del líder del Cártel de Sinaloa, Joaquín El Chapo Guzmán, desde el penal de máxima seguridad El Altiplano representa un duro revés en relación a uno de los brazos principales de la Guerra contra el narcotráfico durante el gobierno de Felipe Calderón (2006-2012): la estrategia High Value Target -HVT, por sus siglas en inglés-cuyo objetivo es desarticular a las organizaciones narcotraficantes mediante el abatimiento o detención de sus líderes. A partir de este episodio, el presente artículo analiza el diseño e implementación de la estrategia HVT en el país. Luego, realiza un balance de los resultados obtenidos tras su ejecución. Por último, identifica las principales lecciones que se pueden extraer del caso mexicano.
\end{abstract}

Palabras clave: High Value Target, guerra contra el narcotráfico, crimen organizado.

Este artículo es un producto del Proyecto IN201503, “`Tropas en la calle? Fuerzas Armadas en seguridad pública en México y El Salvador: Una visión comparada”. Financiado por la Academia Nacional de Estudios Políticos y Estratégicos (ANEPE).

** Analista en Políticas y Asuntos Internacionales mención en Seguridad y Defensa, Universidad de Santiago. Investigador Asociado Academia Nacional de Estudios Políticos y Estratégicos, Santiago de Chile. Correo electrónico: jarratia@anepe.cl 


\begin{abstract}
The recent prison break Sinaloa Cartel's leader, Joaquin El Chapo Guzman, from the maximum security prison El Altiplano represents a severe setback in relation to one of the main arms of the War on Drugs during the Felipe Calderon's administration (20062012): High Value Target strategy -HVT, for its acronym in English - which aims to dismantle drug trafficking organizations by gloom or arrest of their leaders. From this episode, this article analyzes the design and implementation of the HVT strategy in the country. Then, make an assessment of the results obtained after his execution. Finally, it identifies key lessons that can be drawn from the Mexican case.
\end{abstract}

Keywords: High Value Target, war on drugs, organized crime.

\title{
Introducción
}

El reciente escape del líder del Cártel de Sinaloa, Joaquín El Chapo Guzmán, desde el penal de máxima seguridad El Altiplano mediante un túnel subterráneo que se extendía por más de un kilómetro desde su ducha — según la versión oficial- significa un duro revés en relación a uno de los brazos principales de la Guerra contra el narcotráfico durante el gobierno de Felipe Calderón (2006-2012): la estrategia High Value Target HVT, por sus siglas en inglés - cuyo objetivo es desarticular a las organizaciones narcotraficantes mediante el abatimiento o detención de sus líderes.

Sin embargo, en abril de 2015 se difundió un oficio confidencial de la Procuraduría General de la República - PGR - que exhibía auspiciosos resultados sobre el combate al crimen organizado. De acuerdo a ese documento, ya se han detenido a 90 de los 120 objetivos considerados como prioritarios para la administración Peña Nieto (Corcoran, 2015). Incluso, en una entrevista concedida al semanario Proceso, Tomás Zerón —director de la Agencia de Investigación Criminal de la PGR - señaló que sólo quedan dos carteles de la droga operativos en México: Cártel de Sinaloa y Cártel de Jalisco Nueva Generación (Lohmulle, 2015). Si bien esa afirmación es cuestionable ${ }^{1}$, refleja una clara

1 De hecho, las afirmaciones del funcionario gubernamental no se condicen con las últimas cifras de la PGR según las cuales en el país actualmente existen nueve carteles activos (Cártel de Sinaloa, Cártel de Jalisco Nueva Generación, Los Zetas, Cártel del Golfo, Cártel de Tijuana, Beltrán Leyva, Cártel de Juárez, La Familia Michoacana y Los Caballeros Templarios) y 45 células criminales. Ver: Lohmulle (2015). 
tendencia en el mundo del hampa azteca impulsada por la aplicación del método HVT: la fragmentación de las organizaciones narcotraficantes en grupos criminales más pequeños, focalizados y flexibles, es decir, muchos carteles actualmente operan como colectivos de células aisladas más que como organizaciones coherentes bajo un mando unificado.

Durante una conversación que sostuvo con The New York Times en octubre de 2011, el ex presidente Calderón declaró:

efectivamente, hemos capturado a la mayoría de los líderes criminales que nos habíamos propuesto, pero no es nuestra única y quizá tampoco nuestra fundamental parte de la estrategia. Básicamente nuestra estrategia tiene tres grandes componentes. Uno es enfrentar, debilitar y neutralizar a los grupos criminales; en ello está ésta parte de capturar a sus líderes, pero no únicamente a los líderes, sino también a sus estructuras intermedias [...]. (Guerrero, 2012)

Bajo esa lógica, cabe mencionar las siguientes consideraciones contextuales sobre el método HVT:

En primer lugar, éste es aplicado habitualmente no sólo contra grupos criminales, sino también contra movimientos insurreccionales u organizaciones terroristas (Pérez Caballero, 2014). En este sentido, la puesta en marcha de esta clase de estrategias por parte de las autoridades suele obedecer a una conceptualización errónea de las organizaciones criminales como movimientos insurrectos -insurgencia criminal-que representan una amenaza directa a la integridad del Estado — buscando desarticular los principales grupos criminales y restablecer la legitimidad institucional en zonas disputadas y perdidas-, llevando a que su combate y resistencia de éstas a la coerción gubernamental adquieran rasgos propios de un conflicto de baja intensidad.

De ese modo, en la Guerra de Afganistán, la estrategia resultó ser exitosa pues

gracias a la focalización de las agencias estadounidenses de inteligencia en la supresión de objetivos de alto valor, se logró inhibir la actividad de varios líderes, se recolectó información precisa sobre la ubicación de otros miembros y el funcionamiento de células operativas importantes, y con ello, se logró la dislocación de una parte sustancial de la estructura de Al Qaeda. (Arnaud, 2013, p. 24) 
Si bien es cierto que a inicios de $2009 \mathrm{Al}$ Qaeda continuaba activa y su máximo líder no había sido capturado todavía, empero "era una sombra de lo que había sido en los años noventa, y Osama bin Laden desempeñaba un papel secundario en las operaciones de la organización, más como un líder moral" (Arnaud, 2013, p. 24) o simbólico hasta su abatimiento en mayo de 2011 durante la operación Lanza de Neptuno planeada por la Agencia Central de Inteligencia - CIA, por sus siglas en inglés-.

En México, el mismo equipo estadounidense responsable de las operaciones de inteligencia llevadas a cabo contra Al Qaeda durante el conflicto en Afganistán estaría a cargo de la instrumentación de una estrategia con similares características contra los carteles de la droga en el marco de la Guerra contra el narcotráfico. Sin embrago, ¿cómo lo harían? La aplicación del método se iniciaría con un proceso de investigación previa para averiguar los nombres de los miembros de las cúpulas de los cárteles. El siguiente paso consistiría en confeccionar un listado de objetivos prioritarios para ser arrestados -basado en intereses mutuos- en el cual figuran 24 cabecillas y 13 lugartenientes de las seis organizaciones narcotraficantes operativas en el país durante 2006 (Servitja, 2012). Luego, se asignarían los roles operativos a cada uno de los actores, o sea, mientras Estados Unidos proveería información de inteligencia para las operaciones, México facilitaría los recursos humanos y técnicos necesarios en la medida que contara con ellos; en su defecto, Estados Unidos se los entregaría. Ambas naciones participarían en el diseño de los operativos.

No obstante, México condicionó el involucramiento de las agencias estadounidenses en los operativos, comprometiéndolas a mantenerse en una segunda línea, de manera tal que el gobierno mexicano no fuera criticado por violaciones a la soberanía nacional y pudiera capitalizar las detenciones en niveles de popularidad y obtención de réditos políticos (Felbab-Brown, 2013). Desde esa perspectiva, en términos de respuesta institucional, la supresión de objetivos de alto valor ofrecía grandes ventajas porque conceptualmente era fácil comprenderla y planificarla; y dado que "su métrica se basa únicamente en el número de objetivos desactivados, es más directa, sencilla y fácil" (Arnaud, 2013, p. 25) de exhibir ante la opinión pública como un avance en la lucha contra el tráfico de drogas.

Por otro lado, la CIA y la Agencia Federal Antidrogas -DEA, por sus siglas en inglés- prepararon a policías mexicanos, más tarde los distribuyeron en seis Unidades de Investigaciones Sensibles - SIU, por sus siglas en inglés - compuestas aproximadamente por 25 agentes (Arnaud, 2013). De esa manera, cada SIU se abocaría a investigar y aprehender a determinados miembros pertenecientes a un mismo cártel. 
En 2007, los presidentes Felipe Calderón y George W. Bush acordaron cooperar en materia de seguridad dando origen a la Iniciativa Mérida con resistencias en sectores nacionalistas mexicanos dada la similitud con el controvertido Plan Colombia, ya que parte del acuerdo implicaba que miembros de los cuerpos de seguridad estadounidenses cumplieran labores en territorio mexicano (Rodríguez, 2010). La iniciativa se enmarcó dentro de la llamada guerra al narcotráfico anunciada por Calderón e incluyó a Centroamérica, República Dominicana y Haití, con el objetivo de "combatir el tráfico de drogas, el tráfico de armas y la violencia generada por el crimen organizado" (Rodríguez, 2010, p. 44).

Previo a su implementación y en un contexto en el que las relaciones entre México y Estados Unidos pasaban por un momento complejo, la Iniciativa Mérida apareció como una opción de política con enfoque de corresponsabilidad mutua (Ramos, 2010). La llegada de Barack Obama a la presidencia en 2008 no implicó mayores cambios a la estrategia de apoyo en equipo y capacitación a las fuerzas de seguridad mexicanas (Meyer, 2010). En diciembre de 2013, Estados Unidos reconoció que la ayuda ascendía, a la fecha, a US $\$ 8$ millones; capacitando a más de 4.500 miembros de la Policía Federal y 1.498 agentes de policías estatales y municipales. Además, se ha avanzado en exigir a México mejorar en transparencia y accountability (rendición de cuentas) por parte de las fuerzas policiales (Meyer, 2014). Sin embargo, esta situación ha sido a costa de ceder espacios de acción exclusivos del Estado a una iniciativa extranjera, centrada, como ya se mencionó, en la corresponsabilidad de ambas partes en esta problemática.

\section{¿Error de cálculo?}

Como señala Arnaud (2013) en el diseño e implementación de la estrategia HVT se trató de encuadrar el fenómeno de inseguridad mexicano dentro de parámetros preexistentes. La experiencia que tuvo mayor peso al momento de decidir aplicar este método fue el caso de Al Qaeda durante la Guerra de Afganistán, situación en la cual se había conseguido desmantelar la organización terrorista, suprimiendo objetivos de alto valor. No obstante, se realizó una suerte de copy-paste pues "al emplear esta referencia de forma rígida, se pasaron por alto diferencias contextuales y estructurales" (Felbab-Brown, 2013, p. 12).

De partida el ambiente operacional de Al Qaeda era bastante diferente al panorama criminal mexicano. En efecto, a mediados de la década pasada éste último se caracterizaba por ser multipolar en razón de que estaba compuesto por seis cárteles principales 
que se repartían las rutas comerciales de modo relativamente equitativo por lo que poseían capacidades y recursos de similar naturaleza. Cada cártel funcionaba con cierto nivel de autonomía territorial en un equilibrio precario, en donde un área o zona pérdida por uno era rápidamente apropiada por una agrupación enemiga. Así,

esta tensión estructural generada por un entorno hipercompetitivo provocaba que, ante el eventual debilitamiento temporal - por una detención, el decomiso de un cargamento importante o el bloqueo de una ruta o punto de salida a Estado Unidos-, cada organización criminal invirtiera una parte sustancial de sus recursos en armamento, de forma que pudiera aguantar el asedio rival mientras restablecía sus redes, es decir, las organizaciones narcotraficantes mantenían una especie de carrera armamentista preventiva. (Arnaud, 2013, p. 26)

En cambio, el contexto operacional de las organizaciones terroristas islámicas no puede catalogarse como hipercompetitivo debido a la naturaleza de sus metas - los carteles tienen una motivación económica, mientras que los terroristas adhieren a una causa político-ideológica-. Esto significa que, por ejemplo, no existe una competencia entre células de Al Qaeda y Hezbolá por perpetrar el ataque terrorista con mayor impacto mediático o número de bajas. Y si bien es posible observar que cada organización actúa de manera autónoma, en algunas ocasiones se han detectado patrones cooperativos por ejemplo Hamas y Hezbolá comparten redes de financiamiento y proveedores de armamento (Arnaud, 2013). En consecuencia, al debilitarse o incapacitarse una célula terrorista no se abre una ventana de oportunidad para otra como sucede en el mundo del narcotráfico.

Sumado a lo anterior, la estrategia HVT está basada en una serie de asunciones que al aplicarse a la Guerra contra el narcotráfico en México resultan ser erróneas. En primer lugar, la capacidad regenerativa que poseen las organizaciones narcotraficantes respecto a los cabecillas abatidos o capturados es mucho mayor en comparación a los grupos terroristas porque el tipo de liderazgo ejercido por un capo de la droga tiende a ser menos complejo que la autoridad funcional al interior de un grupo terrorista. Es decir, un cártel mexicano puede realizar un recambio de dirigentes con menor dificultad pues la importancia de éstos radica principalmente en "su capital social -por ejemplo, vínculos personales en redes familiares, relaciones a largo plazo con proveedores y clientes, etc-, el cual es transferible a otros integrantes del grupo familiar" (Ríos, 2012, p. 146). Además, nuevas organizaciones narcotraficantes siempre surgirán mientras exista el mercado ilícito de drogas y la capacidad de aplicación de la ley sea débil. 
En segundo término, una estrategia de desactivación de objetivos de alto valor supone que "las organizaciones criminales son jerárquicas, centralizadas y que la disponibilidad de líderes es limitada, por lo que la detención de un individuo clave descompondrá la capacidad operativa" (Felbab-Brown, 2013, p.13) de ellas en su conjunto. En consecuencia, la neutralización de un líder será mucho más efectiva en una organización altamente centralizada y jerárquica que en una organización con una estructura horizontal, formada por células semiautónomas. En efecto,

algunas de las organizaciones criminales mexicanas están transitando hacia estructuras organizacionales horizontales, en los que el jefe regional o jefe de sicarios cuenta con alto grado de discrecionalidad sobre las operaciones de su célula - por ejemplo, Los Zetas- de forma destacada. (Arnaud, 2013, p. 26)

En estas situaciones, la aprehensión de capos difícilmente conseguirá desmantelar la organización, por el contrario, ocasionará su fragmentación en múltiples grupos a escala local como se verá más adelante.

Asimismo, la lógica inherente a HVT presume que "existe un alto nivel de disciplina interna y con mecanismos sucesorios definidos, de manera tal, ante el vacío de liderazgos, no surgirá una guerra sucesoria" (Arnaud, 2013, p. 26). En este sentido, cabe destacar que ni cárteles ni grupos terroristas cuentan con reglas establecidas, sin embargo, la distinta naturaleza de sus objetivos hace que las organizaciones criminales sean mucho más propensas que las terroristas a recurrir a la violencia ante una crisis sucesoria. Como se señaló con anterioridad, "el objetivo principal de un narcotraficante es el enriquecimiento ilícito y de manera inmediata, por lo que tiene grandes incentivos para hacerse del vacío desocupado por un aliado o competidor por cualquier medio" (Arnaud, 2013, p. 27). En cambio, el terrorista carece de incentivos para disputar violentamente una posición vacante porque su meta - sea la expulsión de Estados Unidos del Medio Oriente o la recuperación del territorio ocupado por Israel—consiste en obtener un bien intangible a largo plazo, por el que está dispuesto a luchar por un período prolongado.

Por lo tanto, una estrategia eficaz de identificación de targets debe construirse sobre un análisis pormenorizado de las dinámicas internas de las organizaciones criminales, que sea capaz de detectar los nodos críticos para la operación de los cárteles. Empero, éstos últimos no siempre se encuentran en los cuadros superiores ni entre los miembros de alta jerarquía, sino que pueden situarse entre líderes regionales o locales, contadores e incluso servidores públicos corruptos. Además, "el análisis de las dinámicas internas también permite identificar las cadenas sucesorias en las organizaciones y diferenciar a 
los miembros moderados de aquellos propensos a la violencia o a fragmentar la organización" (Arnaud, 2013, p. 28). Esta información se torna crítica al momento de predecir las líneas de acción que pueden adoptar las organizaciones tras la captura o abatimiento de un líder.

De esa manera, el surgimiento de conflictos al interior de todas las organizaciones tras la detención de algunos de los objetivos prioritarios es muestra no sólo de que los cárteles son organizaciones inestables, sino que el trabajo de inteligencia fue insuficiente para medir las consecuencias de las detenciones. O sea, es natural que con posterioridad a la detención de un líder se presente algún tipo de crisis sucesoria dentro de la organización criminal amputada. Sin embargo, también es posible mitigar la intensidad de la violencia generada post-decapitación siempre y cuando se localicen las probables fuentes de violencia y se bloqueen de manera preventiva, antes de llevar a cabo la aprehensión.

Otra falla en la aplicación de la estrategia HVT radica en la ambigüedad de definición de las metas, analizada previamente pues "Felipe Calderón se refería al número de objetivos detenidos y abatidos como uno de los principales avances en seguridad, e ignoraba los incrementos de las ejecuciones, los secuestros y las extorsiones" (Arnaud, 2013, p. 27), los que debían ser los principales indicadores. El énfasis del gobierno federal en medir los avances de la estrategia única y exclusivamente considerando la cantidad de cabecillas detenidos mermó el nivel de confianza de la población en las medidas tomadas por el Ejecutivo en materia de seguridad básicamente por dos motivos: "en primer lugar, subrayó el carácter punitivo de la estrategia sobre otros componentes, como la prevención o el fortalecimiento institucional; y segundo, la ciudadanía percibió una disociación entre el discurso oficial y la realidad" (Arnaud, 2013, p. 27). Por ejemplo en el caso de la neutralización de líderes de Al Qaeda,

el propósito del gobierno estadounidense era disminuir al mínimo el riesgo de atentados terroristas contra de blancos nacionales, y la desarticulación de Al Qaeda constituía un medio para lograr el objetivo final, mas no es un fin en sí mismo. (Arnaud, 2013, p. 28)

Esto significa que el principal criterio utilizado para evaluar el grado de efectividad de la estrategia, es la ausencia de atentados terroristas de alto impacto y no la incapacitación de Al Qaeda en sí misma.

Accesoriamente la rigidez en el listado de objetivos prioritarios le jugó en contra al gobierno federal pues la posibilidad de modificar la priorización de objetivos según 
la coyuntura nacional e internacional y comunicar oportunamente las razones del nuevo ordenamiento pueden utilizarse para alterar el comportamiento de las organizaciones criminales en razón de que permiten focalizar los recursos en desactivar a aquellos miembros o bloques más propensos a actuar imprudentemente o castigar determinados modus operandi, como el uso indiscriminado de la violencia - como Los Zetas- (Guerrero, 2012). Sin embargo, el gobierno mexicano, al no cambiar el listado ni comunicar los criterios para definir sus targets "no sólo desperdició un recurso disuasivo importante, sino que fomentó en los cárteles una mayor disposición para recurrir a la violencia" (Arnaud, 2013, p. 28) pues al ejercerla su ubicación en el ranking permanecía intacta, y por el contrario, no utilizarla implicaba una mella frente a las organizaciones rivales. Por ejemplo, entre julio de 2011 y julio de 2013 fue capturada o abatida prácticamente toda la cúpula de Los Zetas. Aunque esto no implicó la destrucción de la agrupación, sí la debilitó de modo significativo pero, sobre todo, envió una clara señal a las demás organizaciones narcotraficantes: la que emplee brutalidad se convertirá en el foco de atención de las autoridades.

Pese a que, en última instancia, el gobierno mexicano decidió dar prioridad a la orientación de los dos carteles más brutales - La Familia Michoacana y Los Zetas- no obtuvo resultados disuasivos que pudieran ser catalogados como sistémicos. Incluso es posible sostener que los golpes estratégicos propinados por el gobierno a La Familia Michoacana solamente se tradujeron en la irrupción de una nueva pero aún más violenta organización narcotraficante: Los Caballeros Templarios. Igualmente, durante la ejecución de esta estrategia, en más de una ocasión Felipe Calderón tuvo que defenderse de imputaciones sobre un presunto trato preferencial al Cártel de Sinaloa (Guerrero, 2012). Aunque éste último grupo criminal se caracterizaba por ser menos violento en comparación a otros actores como Los Zetas o La Familia Michoacana, fue percibido por la opinión pública mexicana como un caso de favoritismo y complicidad por parte del gobierno. En consecuencia, el Ejecutivo "se vio obligado a negar que dicha orientación diferencial estuviera teniendo lugar y emprendió acciones contra el Cártel de Sinaloa" (Guerrero, 2012) a objeto de aclarar que la interdicción gubernamental era completamente imparcial.

\section{Los resultados obtenidos}

Al comparar el número de capos detenidos o abatidos en las tres administraciones anteriores es evidente el dramático incremento de este tipo de acciones durante el gobierno de Calderón (ver Gráfico 1). De ese modo, a lo largo del periodo de Ernesto 
Zedillo (1994-2000) solo cuatro capos fueron detenidos; durante el gobierno de Vicente Fox (2000-2006) la cifra aumentó a siete. En la era calderonista se consiguió desactivar a 25 de los 37 principales dirigentes de los cárteles — nueve fueron asesinados y 16 aprehendidos-o aproximadamente el $68 \%$ de los objetivos fijados por el gabinete de seguridad como se aprecia en el Tabla 1 (Guerrero, 2012).

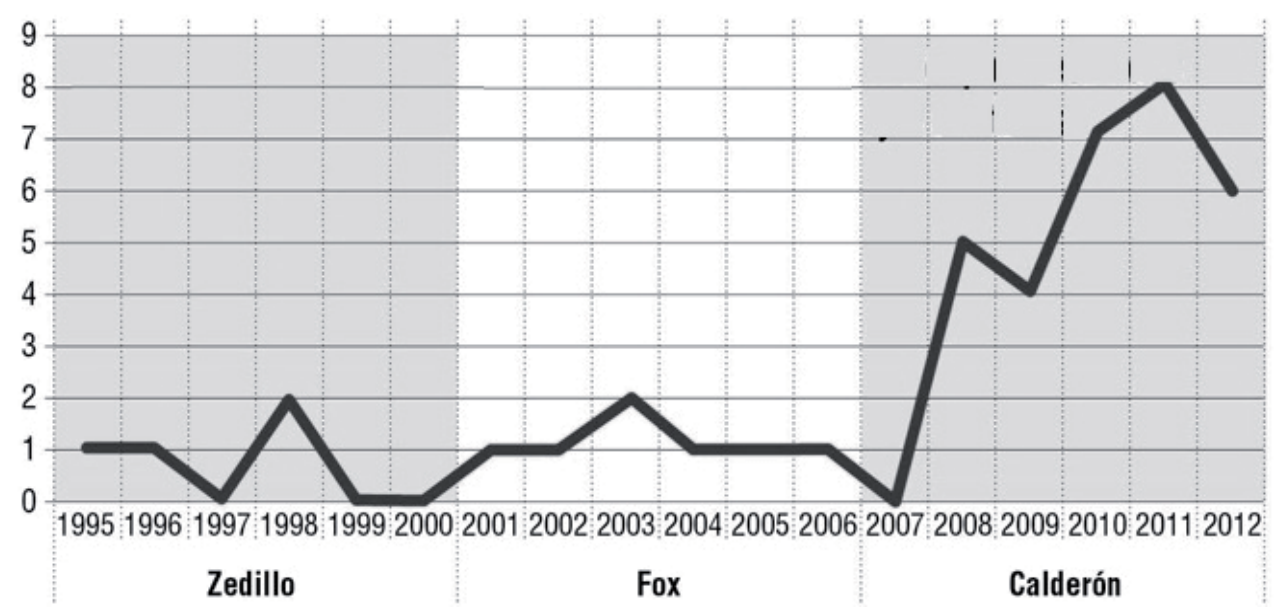

Grafico 1: Capos detenidos o abatidos por sexenio. Fuente: Extraído de Guerrero, E. (2012). 
Tabla 1

Capturas o abatimientos de capos guerra contra narcotráficos (2006-2012)

\begin{tabular}{|c|c|c|c|}
\hline Fecha & Nombre & Cártel & Status \\
\hline Septiembre 2007 & $\begin{array}{l}\text { Sandra Ávila Beltrán,"La } \\
\text { Reina del Pacífico }\end{array}$ & Sinaloa & Libre \\
\hline Enero 2008 & $\begin{array}{l}\text { Héctor Alfredo Beltrán } \\
\text { Leyva, "El Mochomo" }\end{array}$ & Beltrán Leyva & Extraditado \\
\hline Octubre 2008 & $\begin{array}{l}\text { Jesús Zambada García, "El } \\
\text { Rey” }\end{array}$ & Sinaloa & Extraditado \\
\hline Octubre 2008 & Eduardo Arellano Félix & Tijuana & Extraditado \\
\hline Enero 2009 & $\begin{array}{l}\text { Santiago Meza López, "El } \\
\text { pozolero" }\end{array}$ & Sinaloa & Detenido \\
\hline Marzo 2009 & $\begin{array}{l}\text { Vicente Zambada Niebla, "El } \\
\text { Vicentillo" }\end{array}$ & Sinaloa & Extraditado \\
\hline Abril 2009 & Vicente Carrillo Leyva & Juárez & Detenido \\
\hline Abril 2009 & Gregorio Sauceda-Gamboa & Los Zatas & Detenido \\
\hline Diciembre 2009 & Arturo Beltrán Leyva & Beltrán Leyva & Abatido \\
\hline Enero 2010 & $\begin{array}{l}\text { Teodoro García Simental, “El } \\
\text { Teo” }\end{array}$ & Sinaloa & Detenido \\
\hline Marzo 2010 & $\begin{array}{l}\text { José Antonio Medina } \\
\text { Arreguín }\end{array}$ & -- & Extraditado \\
\hline Abril 2010 & Gerardo Álvarez Vásquez & Beltrán Leyva & Detenido \\
\hline Abril 2010 & José Quintero Payán & Juárez & Extraditado \\
\hline Julio 2010 & Ignacio "Nacho" Coronel & Sinaloa & Abatido \\
\hline Agosto 2010 & Edgar Valdez, "La Barbie” & Beltrán Leyva & Detenido \\
\hline Septiembre 2010 & $\begin{array}{l}\text { Sergio Villarreal, "El } \\
\text { Grande" }\end{array}$ & Beltrán Leyva & Extraditado \\
\hline Noviembre 2010 & Ezequiel Cárdenas Guillén & Golfo & Abatido \\
\hline Noviembre 2010 & $\begin{array}{l}\text { Antonio Ezequiel Cárdenas } \\
\text { Guillén, "Tony Tormenta” }\end{array}$ & Golfo & Abatido \\
\hline Enero 2011 & $\begin{array}{l}\text { Flavio Méndez Santiago, "El } \\
\text { Amarillo" }\end{array}$ & Los Zetas & Detenido \\
\hline
\end{tabular}




\begin{tabular}{|c|c|c|c|}
\hline Febrero 2011 & Julián Zapata, "El Piolín” & Los Zetas & Extraditado \\
\hline Junio 2011 & $\begin{array}{l}\text { José de Jesús "El Chango" } \\
\text { Méndez }\end{array}$ & La Familia & Detenido \\
\hline Julio 2011 & $\begin{array}{l}\text { Miguel Ángel Treviño } \\
\text { Morales, “Z- } 40 \text { ” }\end{array}$ & Los Zaetas & Detenido \\
\hline Septiembre 2012 & Eduardo Costilla, "El Coss" & Golfo & Detenido \\
\hline Septiembre 2012 & $\begin{array}{l}\text { Iván Velásquez Caballero, } \\
\text { "Z-50" o "El Talibán" }\end{array}$ & Los Zetas & Detenido \\
\hline Septiembre 2012 & $\begin{array}{l}\text { David Rosales Guzmán, "El } \\
\text { Comandante Diablo" }\end{array}$ & Golfo & Detenido \\
\hline Octubre 2012 & $\begin{array}{l}\text { Heriberto Lazacna, "El } \\
\text { Lazca” }\end{array}$ & Los Zetas & Abatido \\
\hline
\end{tabular}

Fuente: extraído de López, X. y Meza, M. (2015).

Sin embargo, a menudo una política de decapitación intensiva estimula la violencia básicamente por tres vías: 1) conflictos sucesorios al interior de una organización criminal; 2) desprendimiento de sus mandos medios; y 3) generación de cadenas de vacío que son aprovechadas por agrupaciones rivales.

Cuando Felipe Calderón accede a la Presidencia de México en diciembre de 2006, existían sólo cuatro grandes cárteles: Cártel de Sinaloa, Cártel del Golfo, Cártel de Juárez y La Familia Michoacana, pasándose a 10 organizaciones criminales en 2012 (ver Tabla 1 y 2). Asimismo, la geografía y el poder de ellas se fueron transformando de acuerdo con la dinámica que se fue presentando por el accionar de las tres guerras -intra-cártel, inter-cártel y cártel-Estado-. En efecto, el proceso de fragmentación de los cárteles se agudizó particularmente durante el cuarto y quinto año del gobierno de Calderón culminando 2011 con el registro récord de 16 cárteles activos (ver Tabla 2). De ese modo, la división del Cártel de Tijuana en 2007 y la del Cártel de Sinaloa en 2008 propiciaron que para 2009 ya existieran ocho organizaciones narcotraficantes. En 2010 la fragmentación se aceleró sustancialmente puesto que ante el acoso del gobierno federal la Organización Beltrán Leyva se fraccionó en tres agrupaciones regionales y el Cártel del Milenio en dos. Además, un conflicto interno culminó con el desprendimiento de Los Zetas del Cártel del Golfo. 
Tabla 2

Carteles operativos en México (2007 - 2012)

\begin{tabular}{|c|c|c|c|c|c|}
\hline 2007 & 2008-2009 & $\begin{array}{c}2010 \\
\left(1^{\circ} \text { semestre }\right)\end{array}$ & $\begin{array}{c}2010 \\
\left(2^{\circ} \text { semestre }\right)\end{array}$ & 2011 & 2012 \\
\hline \multirow{6}{*}{$\begin{array}{l}\text { Cártel de } \\
\text { Sinaloa }\end{array}$} & $\begin{array}{l}\text { Cártel de } \\
\text { Sinaloa }\end{array}$ & $\begin{array}{l}\text { Cártel de } \\
\text { Sinaloa }\end{array}$ & $\begin{array}{l}\text { Cártel de } \\
\text { Sinaloa }\end{array}$ & $\begin{array}{l}\text { Cártel de } \\
\text { Sinaloa }\end{array}$ & $\begin{array}{l}\text { Cártel de } \\
\text { Sinaloa }\end{array}$ \\
\hline & \multirow{5}{*}{$\begin{array}{l}\text { Cártel de } \\
\text { los Beltrán } \\
\text { Leyva }\end{array}$} & \multirow{3}{*}{$\begin{array}{l}\text { Cártel del } \\
\text { Pacífico Sur }\end{array}$} & \multirow{3}{*}{$\begin{array}{l}\text { Cártel del } \\
\text { Pacífico Sur }\end{array}$} & $\begin{array}{l}\text { Cártel del } \\
\text { Pacífico Sur }\end{array}$ & $\begin{array}{l}\text { Cártel del } \\
\text { Pacífico Sur }\end{array}$ \\
\hline & & & & $\begin{array}{l}\text { La Mano con } \\
\text { Ojos }\end{array}$ & Extinto \\
\hline & & & & $\begin{array}{l}\text { La Nueva } \\
\text { Administración }\end{array}$ & Extinto \\
\hline & & \multirow[t]{2}{*}{$\begin{array}{l}\text { Cártel de la } \\
\text { Barbie }\end{array}$} & $\begin{array}{l}\text { Cártel } \\
\text { Indepen- } \\
\text { diente de } \\
\text { Acapulco }\end{array}$ & $\begin{array}{l}\text { Cártel } \\
\text { Independiente } \\
\text { de Acapulco }\end{array}$ & Extinto \\
\hline & & & $\begin{array}{l}\text { Cártel del } \\
\text { Charro }\end{array}$ & Extinto & Extinto \\
\hline $\begin{array}{l}\text { Cártel de } \\
\text { Juárez }\end{array}$ & $\begin{array}{l}\text { Cártel de } \\
\text { Juárez }\end{array}$ & $\begin{array}{l}\text { Cártel de } \\
\text { Juárez }\end{array}$ & $\begin{array}{l}\text { Cártel de } \\
\text { Juárez }\end{array}$ & Cártel de Juárez & $\begin{array}{l}\text { Nuevo Cártel } \\
\text { de Juárez }\end{array}$ \\
\hline \multirow{2}{*}{$\begin{array}{l}\text { Cártel de } \\
\text { Tijuana }\end{array}$} & $\begin{array}{l}\text { Cártel de } \\
\text { Tijuana }\end{array}$ & $\begin{array}{l}\text { Cártel de } \\
\text { Tijuana }\end{array}$ & $\begin{array}{l}\text { Cártel de } \\
\text { Tijuana }\end{array}$ & $\begin{array}{l}\text { Cártel de } \\
\text { Tijuana }\end{array}$ & $\begin{array}{l}\text { Cártel de } \\
\text { Tijuana }\end{array}$ \\
\hline & $\begin{array}{l}\text { Facción de } \\
\text { El Teo }\end{array}$ & $\begin{array}{l}\text { Facción de } \\
\text { El Teo }\end{array}$ & Extinto & Extinto & Extinto \\
\hline \multirow{2}{*}{$\begin{array}{l}\text { Cártel del } \\
\text { Golfo }\end{array}$} & \multirow{2}{*}{$\begin{array}{l}\text { Cártel del } \\
\text { Golfo-Los } \\
\text { Zetas }\end{array}$} & $\begin{array}{l}\text { Cártel del } \\
\text { Golfo }\end{array}$ & $\begin{array}{l}\text { Cártel del } \\
\text { Golfo }\end{array}$ & Cártel del Golfo & $\begin{array}{l}\text { Cártel del } \\
\text { Golfo }\end{array}$ \\
\hline & & Los Zetas & Los Zetas & Los Zetas & Los Zetas \\
\hline \multirow{4}{*}{$\begin{array}{l}\text { La Familia } \\
\text { Michoacana }\end{array}$} & \multirow{4}{*}{$\begin{array}{l}\text { La Familia } \\
\text { Michoacana }\end{array}$} & \multirow{4}{*}{$\begin{array}{l}\text { La Familia } \\
\text { Michoacana }\end{array}$} & \multirow{4}{*}{$\begin{array}{l}\text { La Familia } \\
\text { Michoacana }\end{array}$} & $\begin{array}{l}\text { La Familia } \\
\text { Michoacana }\end{array}$ & $\begin{array}{l}\text { La Familia } \\
\text { Michoacana }\end{array}$ \\
\hline & & & & $\begin{array}{l}\text { Los Caballeros } \\
\text { Templarios }\end{array}$ & $\begin{array}{l}\text { Los } \\
\text { Caballeros } \\
\text { Templarios }\end{array}$ \\
\hline & & & & $\begin{array}{l}\text { Los } \\
\text { Incorregibles }\end{array}$ & Extinto \\
\hline & & & & La Empresa & Extinto \\
\hline
\end{tabular}




\begin{tabular}{|c|c|c|c|c|c|}
\hline \multirow[b]{2}{*}{$\begin{array}{l}\text { Cártel del } \\
\text { Milenio }\end{array}$} & \multirow[b]{2}{*}{$\begin{array}{l}\text { Cártel del } \\
\text { Milenio }\end{array}$} & \multirow[b]{2}{*}{$\begin{array}{l}\text { Cártel del } \\
\text { Milenio }\end{array}$} & La Resistencia & La Resistencia & $\begin{array}{l}\text { La } \\
\text { Resistencia }\end{array}$ \\
\hline & & & $\begin{array}{l}\text { Cártel de } \\
\text { Jalisco- Nueva } \\
\text { Generación }\end{array}$ & $\begin{array}{l}\text { Cártel de } \\
\text { Jalisco- Nueva } \\
\text { Generación }\end{array}$ & $\begin{array}{l}\text { Cártel de } \\
\text { Jalisco- } \\
\text { Nueva } \\
\text { Generación }\end{array}$ \\
\hline & & & & $\begin{array}{l}\text { La Nueva } \\
\text { Federación para } \\
\text { Vivir Mejor }\end{array}$ & Extinto \\
\hline 6 & 8 & 10 & 11 & 16 & 10 \\
\hline
\end{tabular}

Fuente: extraído de Guerrero 2012

Así, para 2012 en México operaban —además de los mencionados previamente- el Cártel del Pacífico Sur, Cártel de Tijuana, Los Caballeros Templarios y Los Zetas. Igualmente, hay dos grupos que adquirieron notoriedad entre las organizaciones de menor rango: el Cártel de Jalisco-Nueva Generación -CJNG- y La Resistencia. De lo anterior es posible advertir que los cárteles de Sinaloa, del Golfo, de Juárez y La Familia Michoacana dan muestra de una mayor resistencia a la presión gubernamental. O sea, su nivel de estabilidad es alto, lo cual se traduce en una capacidad de permanencia o auto conservación relevante. Cabe señalar que esta última dependerá, principalmente, de su "resiliencia en tanto redes ilícitas que, en última instancia, permite determinar si una organización narcotraficante es capaz de resistir la captura de sus cabecillas y, de lograrlo, cómo evoluciona" (Salcedo-Albarán y Garay, 2012, pp. 12-13).

En consecuencia, el presidente panista fracasó en el objetivo de lograr la fragmentación total del mundo criminal. Es más, han surgido cuestionamientos sobre el método utilizado por el gobierno federal para lograr dicha fragmentación al considerar que el enfoque uno por uno puede ser más efectivo para luchar contra los cárteles. Ese enfoque sugiere que la política de seguridad debería priorizar un objetivo y focalizar el combate en un cártel particular, y una vez derrotado o debilitado, centrarse en acabar con el siguiente en el ranking y así sucesivamente. De hecho, Mark Kleiman (2011) publicó un trabajo titulado Surgical strikes in the drug wars, en el cual plantea que el principal error cometido por Calderón radicó en emprender una ofensiva simultánea contra todos los cárteles operativos teniendo varios frentes abiertos contra ellos. Siguiendo esa misma lógica, Guerrero (2012) plantea que ningún Estado tiene la suficiente capacidad para 
combatir a todos los grupos criminales de forma paralela, y si lo hace, el resultado será ineficaz.

El caso más conocido de aplicación del enfoque uno por uno es la Colombia de los 90 cuando los Cárteles de Cali y de Medellín se disputaban el mercado de la droga. En aquel entonces, la estrategia de seguridad del entonces presidente Ernesto Samper (19941998) consistió en atacar al Cártel de Medellín en primer lugar. Y una vez eliminada su cúpula, los esfuerzos se dirigieron hacia el Cártel de Cali. ¿Qué resultados tuvo esta línea de acción? La eliminación de los dos cárteles al cabo de una década de implementación. Sin embargo, de acuerdo a Felbab-Brown (2013), cuando se ejecuta el enfoque uno por uno se debe considerar el contexto de aplicación. Así, en Colombia sólo existían dos grandes cárteles y ningún cártel de menor jerarquía estaba en disposición de ocupar el vacío de poder dejado por ambos grupos criminales. Mientras que en México, existían otras organizaciones narcotraficantes - aparte del Cártel de Sinaloa o Los Zetas-con alcance estatal como el Cártel del Golfo, eso sin contar el potencial y las capacidades que poseían los cárteles de "peaje" y regionales. En definitiva, emplear el método uno por uno en la situación que enfrentaba Calderón era complejo.

Pese a ello, a mediados de 2011 el gobierno federal puso en marcha el operativo Lince Norte, seguido de otro llamado Escorpión, orientados a debilitar a Los Zetas. Ambos planes permitieron aprehender tanto a miembros activos de esa organización como a policías corruptos vinculados a ella. Empero, cabe destacar que esas operaciones marcan un punto de inflexión en la medida que representan un ajuste mayor a la estrategia anticrimen: dirigir los esfuerzos y capacidades en una organización criminal específica (Guerrero, 2012). Esto significó que durante el último año del sexenio calderonista la política de detenciones ya no se aplicó de modo indiscriminado - como sucedió en los primeros cinco años de gobierno- sino que se concentró en detener a mandos superiores de Los Zetas-. Pero cabe preguntarse ¿Por qué el esfuerzo gubernamental se volcó únicamente a Los Zetas? Porque se trataba de una organización delictiva altamente violenta que se había expandido con gran rapidez, y había diversificado sus flujos de ingreso hacia otras actividades ilícitas como extorsión, secuestro, robo de combustible, trata de personas y robo de vehículos - además del tráfico transnacional de drogas-. Un indicador de tal cambio es la cantidad de aprehensiones de líderes pertenecientes a Los Zetas en relación con los del Cártel de Sinaloa - su principal rival y organización equiparable en términos operacionales y dominio territorial-. Como lo muestra el Gráfico 2, al contrastar las capturas de dirigentes de ambas organizaciones criminales mexicanas, se aprecia claramente que durante 2012 la prioridad fue arrestar a cabecillas de Los Zetas. 


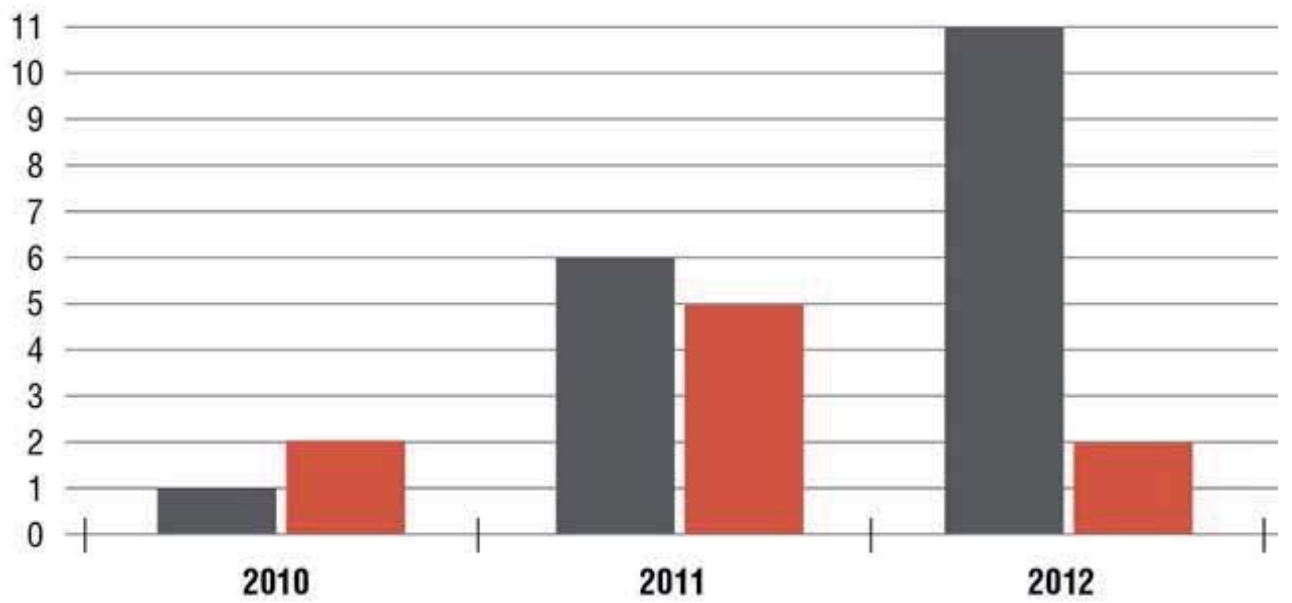

Zetas $\square$ Sinaloa

Gráfico 2: Capturas y abatimientos de líderes Cártel de Sonaloa y Los Zatas (2010 2012*). Fuente: Extraído de Guerrero (2012).* hasta el 10 de octubre.

Por otro lado, se ha abierto una discusión en torno al impacto del método HVT en los niveles de violencia pues extraer lecciones incompletas o distorsionadas pasando por alto las grandes complejidades u omitiendo las particularidades de la experiencia afgana puede socavar profundamente la eficacia de los resultados obtenidos tras la ejecución de políticas emuladas, pudiendo éstos ser a veces incluso contraproducentes. Eso fue precisamente lo que sucedió en México durante la administración de Felipe Calderón, quien abrazó con entusiasmo la exitosa narrativa sobre HVT contra Al Qaeda pero la falta de priorización y claridad operativa en su implementación intensificó, en gran medida, la violencia vinculada con la criminalidad organizada.

Se estima que durante el segundo gobierno panista entre 47.000 y 60.000 personas murieron producto de la violencia asociada al narcotráfico - 12.366 en 2011 y más de 12.000 en 2012-. Tales niveles de violencia superan ampliamente los registrados en Afganistán -1.948 en 2013 - un país sumido en un conflicto armado (Datos macro, 2015). En diversas ocasiones, Calderón argumentó que el incremento de la violencia se debía a la eficacia del gobierno en la interdicción de las organizaciones narcotraficantes. En efecto, parte de la doctrina plantea que HVT habría sido uno de los factores que provocaron un aumento de la violencia en el sexenio de Calderón (Guerrero, 2011). 
En estrecha relación con lo anterior cabe señalar que si bien los aspectos económicos del mercado de la droga - demanda, oferta y precio - parecieran estar vinculados con el aumento de la violencia entre cárteles y el Estado, los cambios en las acciones estatales también juegan un rol gravitante. En este contexto, resulta particularmente importante reconocer que el punto de inflexión desde 2006 fue la política del gobierno mexicano. Así la transferencia en el nivel ejecutivo fue acompañada por una modificación conductual a nivel federal: Fox, y a mayor grado Calderón, buscaron disminuir el poder e influencia política de las organizaciones criminales. De ese modo, México comenzó a sufrir una violencia de transición, vale decir, las acciones policiaco-militares mexicanas contra las organizaciones narcotraficantes las debilitaron pero no transfirieron el poder del Estado o de otro grupo criminal (Williams, 2010). Mientras que las acciones del Estado rompieron el equilibrio de poder entre los narcotraficantes y su capacidad para controlar el territorio y el contrabando de rutas y el poder para disuadir a sus oponentes. Por ende, el equilibrio de poder en el mercado ilícito de los carteles fue sustituido por una rivalidad abierta entre el crimen organizado y el Estado.

En este sentido, una cuestión clave es la decisión respecto a dónde y cuándo aplicar medidas represivas, o sea, si el Estado aplica el mismo nivel de fuerza a todas las organizaciones criminales, independientemente de su comportamiento - represión generalizada - o si el Estado ejerce la represión en proporción a la cantidad y gravedad de la violencia empleada por los cárteles — respuesta proporcional-. Sin embargo, la administración de Calderón rara vez realizó tal distinción — salvo en el caso de Los Zetas en 2011 como se indicó más arriba-, investigaciones recientes muestran que la represión generalizada no genera desincentivos para el uso de la violencia por parte de los actores armados no estatales, e incluso puede tener un influjo determinante en las acciones de las organizaciones narcotraficantes como la decisión de generar una escalada de violencia. En efecto, el ex presidente panista llamó al ejército para combatir indiscriminadamente a los cárteles de la droga, y éstos últimos respondieron con inusitada violencia. Es decir, los cárteles reaccionaron ante la ofensiva de Calderón con una campaña deliberada contra las fuerzas gubernamentales.

En este escenario, los ataques por parte de los cárteles contra jefes de policía, y soldados estuvieron pensados como una forma de presionar al Estado para evitar la confrontación y restablecer un espacio en que las organizaciones delictivas puedan gozar de un alto grado de impunidad, como dijo un ex jefe de operaciones internacionales de la DEA se trató de "un proceso de intimidación [...] querían enviar un mensaje. Si no cooperas, te vamos a meter unos balazos" (International Crisis Group, 2013, p. 24). Con un gobierno menos permisivo era inevitable que los enfrentamientos entre los traficantes 
y los cárteles se volvieran más frecuentes. Por ende, una consecuencia no deseada que se obtuvo del HVT es el incremento de la violencia contra autoridades tanto a nivel local, estatal y federal. Así, la violencia contra la autoridad pública entra en la espiral ascendente de acción-reacción: cuanto más se reprime a un cártel, más aumenta la violencia contra objetivos públicos como las fuerzas de seguridad. De hecho, entre 2006 y 2011 existió una correlación positiva entre el número de ataques al ejercito por partes de los carteles y el nivel de fragmentación de éstos últimos como indica el Gráfico 3.

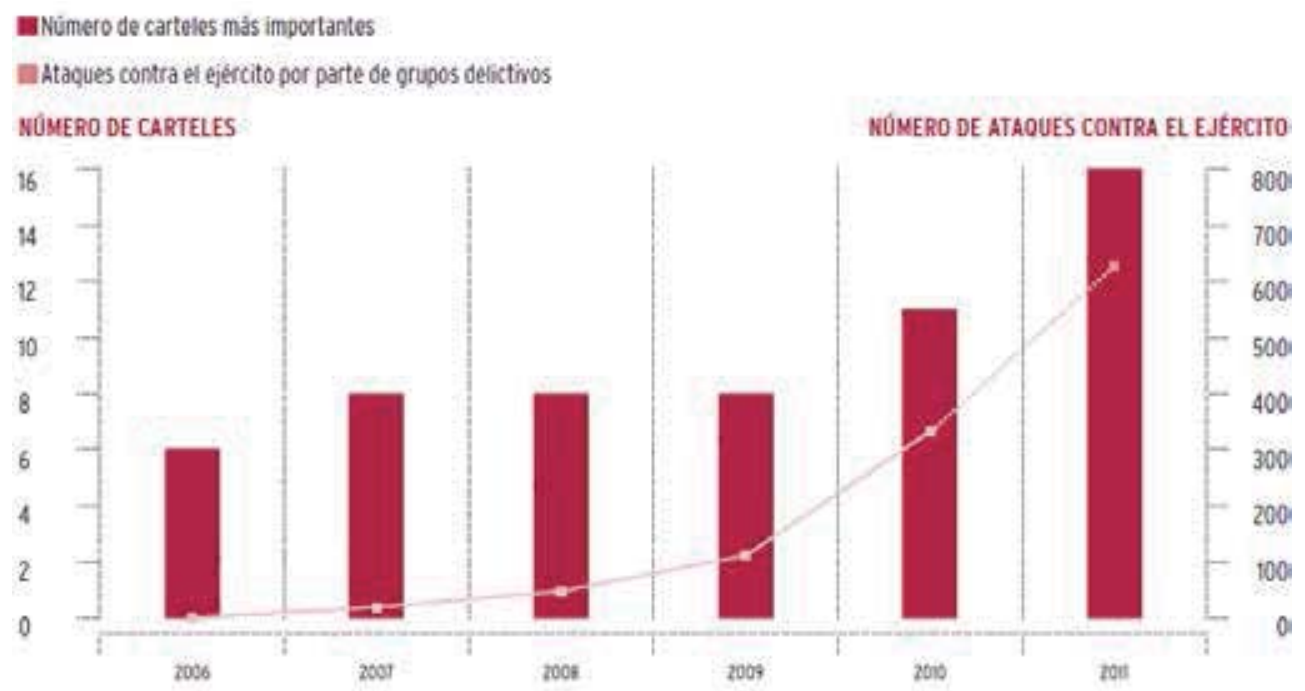

Gráfico 3: Fragmentación de carteles y ataques contra el ejército mexicano (2006 2011). Fuente: Elaboración propia a partir de datos extraídos de Lessing (2014)

Igualmente, la cantidad de choques protagonizados por SEDENA y presuntos miembros del crimen organizado tuvo un crecimiento acelerado entre 2007 y 2011 para luego descender en 2012 como se observa en el Grafico 4. De hecho, los militares alcanzaron su peak de enfrentamientos en 2011: 1.009, cifra que se redujo aproximadamente un $20 \%$ al año siguiente (Pérez, Silva y Gutiérrez, 2015). Esa disminución podría obedecer a diversos factores explicativos: un menor despliegue de elementos de las fuerzas federales, variaciones en el número y características de los operativos realizados, así como la reconfiguración o desplazamiento de las organizaciones criminales a regiones o territorios cuya capacidad de respuesta estatal es menor — como se explicará más adelante-. 


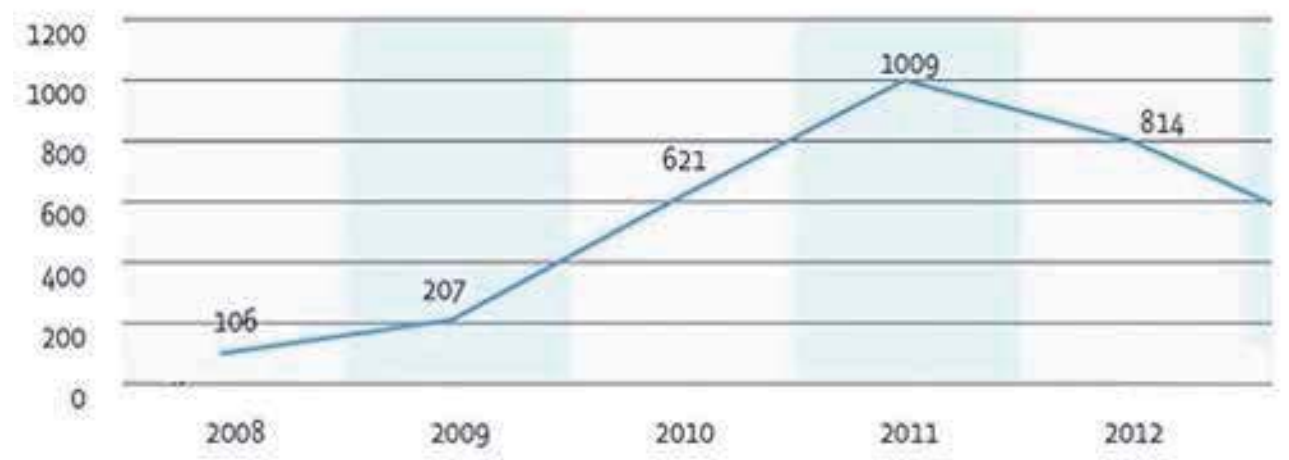

Gráfico 4: Enfrentamiento entre SEDENA y presuntos miembros del crimen organizado (2008- 2012). Fuente: Modificado desde Pérez, Silva y Gutiérrez (2015).

El enfrentamiento directo contra fuerzas de seguridad solo sobreviene cuando el umbral de supervivencia de la organización narcotraficante se encuentra amenazado por un entorno hostil. Incluso, el sentido común sugiere que ese actor armado prefiere evitar la confrontación con el Estado ya que resulta ser demasiado costosa y perturbadora para el desarrollo de sus economías ilícitas. Es decir, la violencia sistémica, organizada y estratégica surge cuando a los traficantes les resulta más rentable o ventajoso utilizar la violencia. Tales decisiones están relacionadas con complejas interacciones entre las organizaciones criminales y las fuerzas de seguridad, no solamente en función del tamaño o rentabilidad del mercado ilegal.

Existe otra dimensión que guarda relación con cómo las estrategias de decapitación llevada a cabo por las fuerzas federales, crean, en mayor o menor grado, cadenas de vacío. La estrategia HVT puede dar pie a una cadena de vacío dentro de la organización, y hacer de ésta un objetivo más atractivo para sus rivales. Mientras más extensas sean estas cadenas de vacío y mayores las incertidumbres sobre sucesión interna, más intensa se tornará la competencia generando un mayor nivel de violencia. Esto significa que cada vez que un capo es capturado o abatido gran cantidad de los contratos informales que rigen las relaciones entre la cúpula y los mandos medios se diluyen (Williams, 2010). Lo cual tiene un impacto en la distribución de las utilidades al interior de la organización y en las relaciones de poder en las que se funda su cohesión interna. Las organizaciones criminales pueden transitar, sin dividirse, relevos planeados de liderazgo e, incluso, la detención o muerte de un líder importante. Pero cuando este último tipo de eventos ocurre de manera repetida, genera una mayor agitación en el mercado ilegal, más batallas entre y dentro de las organizaciones de narcotráfico restantes, por lo tanto aumenta la 
probabilidad de que se registren escisiones mayores en la organización provocando una atomización. A modo de ejemplo, la detención de Alfredo Beltrán Leyva —enero 2008-, y los abatimientos de Arturo Beltrán Leyva - diciembre 2009-, Ignacio Coronel — julio 2010 - y Nazario Moreno - diciembre 2010 - constituyeron episodios que propiciaron y exacerbaron la escisión de cárteles.

No obstante, más allá de las disputas y brotes de violencia que tienen lugar por la eventual detención o muerte de algún narcotraficante en la primera línea, la política sistemática e indiscriminada de descabezamiento durante la primera mitad del sexenio de Calderón también cambió las expectativas y preferencias de los mandos medios - jefes de plaza y jefes de sicarios- de los grandes carteles (Felbab-Brown, 2013). Ante el aumento de los riesgos y costes de participar en una extensa organización narcotraficante, muchos de ellos optaron por abandonarla y fundar sus propios grupos criminales a escala local. Varios de estos nuevos emprendimientos criminales se incorporaron inmediata y exitosamente a los mercados de protección ilegal que emergen naturalmente en entornos violentos como los descritos con anterioridad.

Por otra parte, ante la pregunta ¿la decapitación de organizaciones criminales incrementa los niveles de violencia en el corto plazo? analistas como Alejandro Poiré, el otrora secretario técnico del gabinete de seguridad, han planteado, basado en tan sólo en un caso de estudio, que "la caída de capos no multiplica la violencia" (Guerrero, 2011). Su análisis se centra en las tendencias de los homicidios 22 semanas antes y 22 semanas después del abatimiento de Ignacio Coronel — un capo del Cártel de Sinaloa que operaba en Jalisco-. Poiré llega a la conclusión de que tras el abatimiento de Ignacio Coronel, la tendencia de homicidios en la zona disminuyó. Este hallazgo lo lleva a afirmar que "es falsa la hipótesis de que la caída del líder de una organización criminal multiplica la violencia" (Guerrero, 2011). En cambio, Eduardo Guerrero ha defendido una tesis contraria aduciendo que en 22 de 28 casos analizados la detención o abatimiento de un capo produjo un incremento de violencia en su zona de influencia (Guerrero, 2011). Es más, Guerrero ha señalado que los resultados obtenidos del estudio realizado por Poiré carecen de validez pues posee al menos tres deficiencias:

En primer lugar, no es factible que el ex secretario técnico pretenda establecer una generalización sustentándose en caso único. Por lo demás, su trabajo no ofrece mayor justificación para la selección de éste evento en particular. A falta de tal justificación es inevitable pensar que el caso fue escogido porque era el que mejor cuadraba con los argumentos que buscaba defender en el texto. 
En segundo lugar, Poiré sólo atiende el cambio en la tendencia en un periodo muy largo -44 semanas-, lo cual invisibiliza el súbito aumento de la violencia en los días inmediatamente posteriores al abatimiento, el cual sí es evidente cuando se toman en cuenta las cifras absolutas. A juicio de Guerrero, aunque después del abatimiento de Coronel la tendencia de las ejecuciones crece a un ritmo menor, ésta parte de un piso más alto que el registrado previamente, es decir, después de la muerte del integrante del Cártel de Sinaloa se registra en la zona una escalada de violencia. En el Gráfico 5 queda de manifiesto el drástico aumento que registra el nivel mínimo o constante de violencia en el área tras del asesinato de Coronel. Empero, Poiré olvida mencionar el siguiente detalle: después de la muerte de este líder el nivel mínimo o constante de ejecuciones creció de 5,8 ejecuciones por semana a 23,4 por semana, es decir, se incrementó en más del 300\% (Guerrero, 2012).

Estados de Jalisco, Colima y Nayarih, septiembre 2009-diciembre 2010

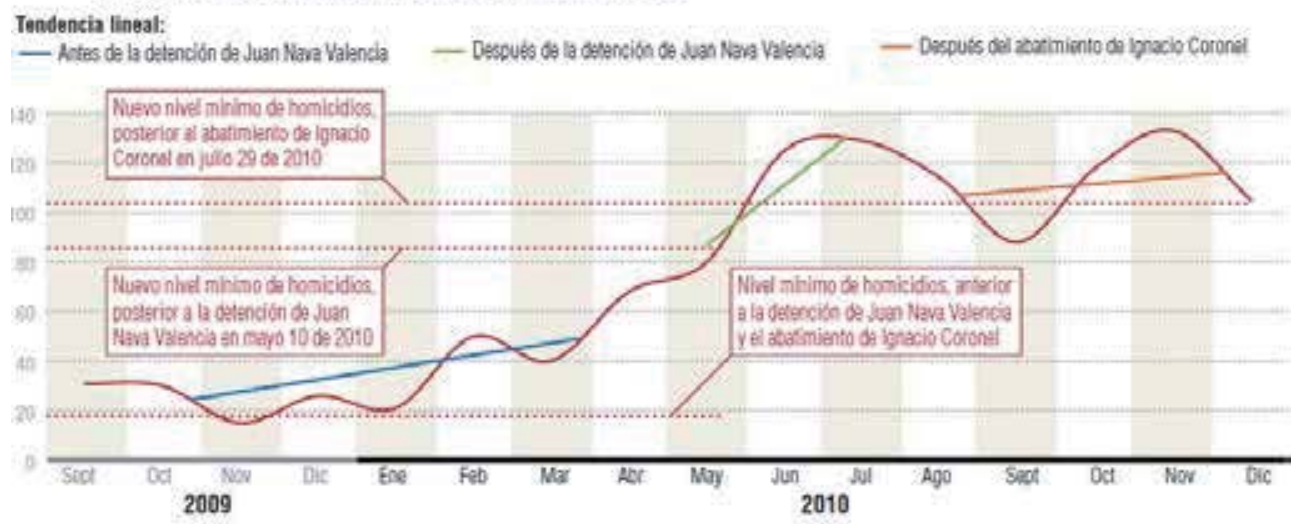

Gráfico 5: Tendencia nivel de violencia antes y después del abatimiento de Ignacio Coronel (2009- 2010). Fuente: Adaptado y modificado de Guerrero (2011).

La tercera deficiencia que detecta Guerrero está vinculada con el argumento circular que propone Poiré para explicar el aumento de la violencia: las tensiones al interior y los conflictos entre los grupos criminales generan violencia, y la violencia genera tensiones internas y conflictos entre los cárteles. En este caso, el conflicto al intra-cártel se refleja en sucesos como el secuestro del hijo y del sobrino de Ignacio Coronel por parte de Los Zetas. Aun asumiendo que parte de la violencia criminal se genera bajo una lógica endógena - como consecuencia de las disputas periódicas dentro de las organizaciones-, esto no contribuye a entender el incremento sistemático de la violencia en el país 
durante el sexenio anterior, además carece de utilidad para deslindar al gobierno de su responsabilidad por el aumento de violencia (Guerrero, 2011).

Por otro lado, cabe subrayar que la fragmentación de los cárteles propició, a su vez, una notoria alza de la violencia vinculada con el crimen organizado desde inicios de 2008 hasta fines de 2011. Este aumento implicó que se revirtiera de forma súbita la tendencia de los homicidios dolosos — que había ido a la baja hasta 2007-, y que la tasa de este delito se duplicara a nivel nacional. Adicionalmente, durante el gobierno de Calderón la violencia del crimen organizado dejó de ser un fenómeno geográficamente acotado. Como se observa en el Gráfico 6, el número de municipios en los que se registró al menos una ejecución mensual en promedio prácticamente se cuadruplicó, al pasar de 51 en 2007 a 194 en 2012. Aunque esta última cifra constituye menos del 10\% de los municipios mexicanos, es importante precisar que en esos 194 ayuntamientos habita casi la mitad de la población a nivel nacional. Al comparar el primer y el último año de gobierno de Calderón se observa que las ejecuciones aumentaron en 28 entidades federativas, en diez de forma acentuada (particularmente en Chihuahua, Guerrero y Coahuila); y disminuyeron — de forma moderada o residual — en cinco (Querétaro, Baja California Sur, Yucatán, Chiapas y Aguascalientes). Al realizar un análisis similar en cada una de las 56 zonas metropolitanas del país se observa un patrón similar. La violencia aumentó en 51 casos y se redujo sólo en cinco: Tijuana, Aguascalientes, Pachuca, Querétaro y Mérida - aunque en las dos últimas la violencia del crimen organizado nunca ha sido significativa-. En definitiva, la violencia se expandió de manera sistemática, y las disminuciones que se observaron fueron insignificantes o en el mejor de los casos excepcionales (Guerrero, 2012). 


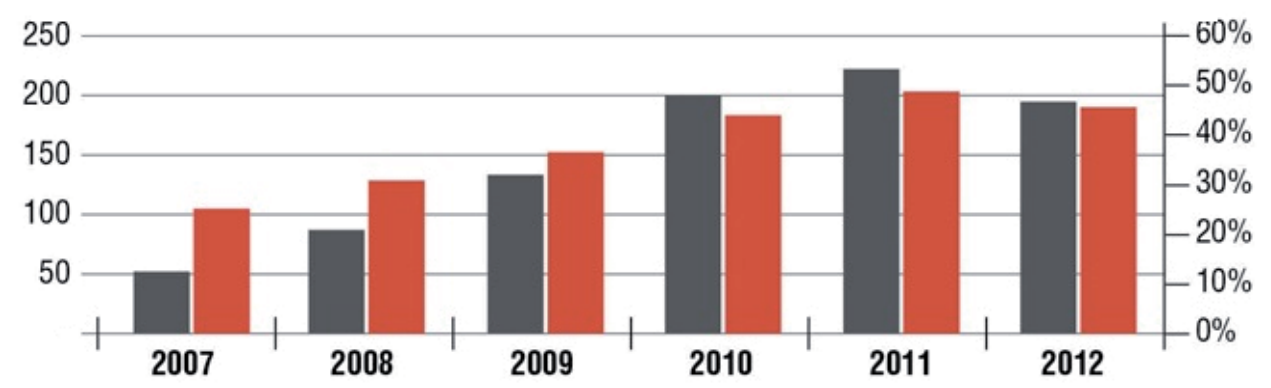

Número de municipios

Porcentaje de la población

Gráfico 6: Municipios en los que se registró al menos una masacre en promedio cada mes y porcentaje de población nacional residente (2007-2012). Fuente: Extraído de Guerrero (2012).

En esa misma dirección, una clase de evento que resulta crítico para detectar la fragmentación criminal son las masacres. La irrupción de comandos armados en lugares públicos, establecimientos mercantiles o viviendas particulares para asesinar a un conjunto de personas, junto con el eventual traslado y abandono de los cadáveres en la vía pública son acciones propias de agrupaciones locales que buscan forjar reputación en el área. Los datos sobre las masacres ocurridas durante el segundo gobierno panista parecen sustentan esa línea argumentativa. Como se aprecia en el Gráfico 7, al cifrar la frecuencia mensual de las masacres que han tenido lugar a lo largo de la administración Calderón es posible identificar que éstas guardan estrecha relación con el proceso de fragmentación criminal y, por ende, con el establecimiento de nuevas organizaciones criminales locales en varios estados de la nación. Durante la primera mitad del sexenio calderonista, se registraron un promedio mensual de 10,3 masacres a lo largo del país; en la segunda mitad este promedio se incrementó a 23,3 masacres (Guerrero, 2012). Igualmente, la distribución geográfica de las masacres respalda aquella hipótesis. Durante 2008 la mayor parte de las masacres se registraron en Baja California, Chihuahua y Sinaloa. En los siguientes años, a medida que los cárteles del centro del país - La Familia Michoacana y Organización Beltrán Leyva- se fraccionaron, las masacres se hicieron habituales en estados como Guerrero, Michoacán, Jalisco, Estado de México, Morelos, Hidalgo, Veracruz y San Luis Potosí (Guerrero, 2012). En síntesis, el aumento de la violencia que ha acompañado el acelerado proceso de fragmentación criminal propiciado por la aplicación del método HVT ha generado mercados de protección ilegal en los que participan grupos criminales 
proclives a cometer actos de violencia escandalosa con fines propagandísticos como las masacres.

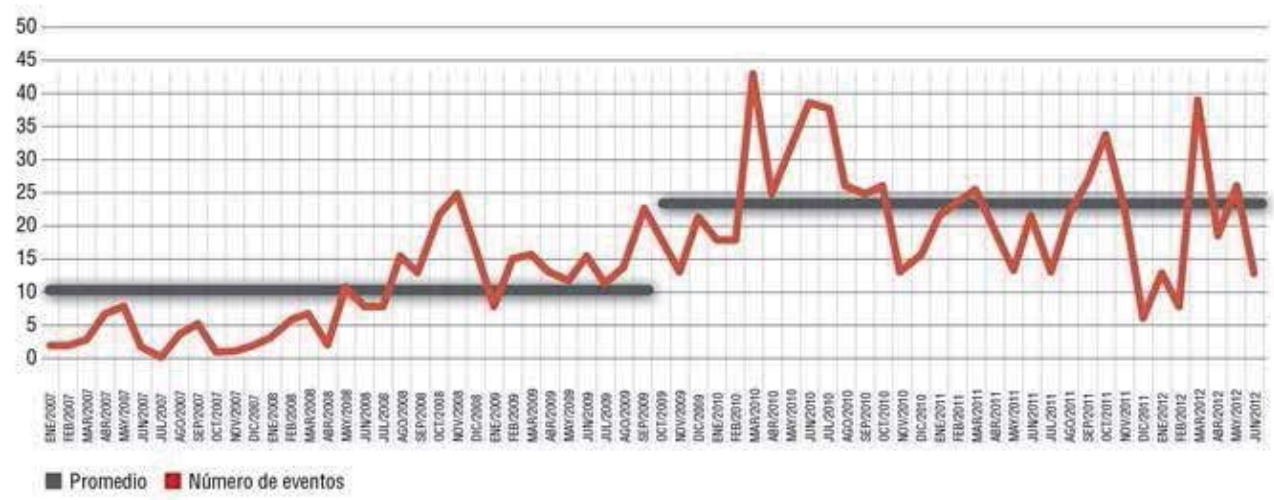

Gráfico 7: Frecuencia mensual de masacres en México (Enero 2007 - Junio 2012). Fuente: Adaptado de Guerrero (2012).

En otro orden de ideas, a largo plazo la fragmentación de los carteles es una buena noticia pues es preferible lidiar con bandas pequeñas sin capacidad para capturar tramos del gobierno federal pero en el corto plazo puede amenazar no sólo a la seguridad nacional, sino vecinal o subregional. Esto debido a que la estrategia HVT impulsada por el ex presidente Felipe Calderón ha sido identificada como el principal catalizador para el desplazamiento del narcotráfico hacia otros países - produciendo el denominado efecto cucaracha- como los que componen el Triángulo Norte de Centroamérica - Guatemala, Honduras y El Salvador- con capacidades de respuesta limitadas y condiciones propicias para su desarrollo, especialmente altos niveles de corrupción e impunidad. Esa área del subcontinente es particularmente atractiva para los cárteles en razón de que éstos se instalan en Estados débiles mas no fallidos. Mientras que un Estado fallido puede no tener alguna estructura institucional real con la cual trabajar, las instituciones estatales débiles ofrecen la oportunidad de cooptar a cuerpos de seguridad, agentes de la fuerza pública, funcionarios judiciales y autoridades políticas. En definitiva, "los Estados determinan la forma o el tipo de la organización criminal que opera y se fortalece en un territorio dado" (Garzón, 2013, p. 12).

De ese modo, el método HVT incrementó los costos humanos y materiales del tráfico de drogas por la frontera norte de México, así como el grado de peligrosidad en las rutas producto de la violencia generada en las disputas, debiéndose buscar rutas 
alternativas, lo cual generó "incentivos para que dicho trafico se relocalizará en la frontera sur del país, utilizando a las naciones del Triángulo Norte como punto de tránsito" (Bagley, 2012, p. 7). Según el reporte Delincuencia organizada transnacional en Centroamérica y el Caribe: Una evolución de las amenazas, publicado por la Oficina de las Naciones Unidas contra la Droga y el Delito - UNODC- en 2012, el Cártel de Sinaloa, Los Zetas y Cártel del Pacífico han trasladado al Triángulo Norte un 90\% de sus operaciones para el tráfico de cocaína hacia Estados Unidos creando a lo largo de la frontera centroamericana nuevas plazas cuyas organizaciones criminales locales han sido cooptadas para librar - en nombre de esos carteles mexicanos- una batalla por el control territorial de los países que integran esa subregión.

De acuerdo con ese informe, el Cártel del Sinaloa ya se encuentra operativo en la región del Pacífico en Guatemala, Honduras y El Salvador, con una incipiente presencia en Nicaragua, Costa Rica y Panamá. En efecto, el Cártel de Sinaloa ha establecido fuertes vínculos con los transportistas más importantes de Guatemala: Los Mendozas — con base en la provincia norteña de Petén - y Los Huistas - que opera en la provincia occidental de Huehuetenango - al parecer le han suministrado drogas al cártel mexicano por más de una década. Igualmente, las principales organizaciones criminales salvadoreñas tienen fuertes conexiones con la organización narcotraficante azteca: El Cártel de Texis —cuya red opera en el noroeste del país - y Los Perrones - ubicados tanto en el oriente como en la región occidente - al parecer se remontan por lo menos a 2002 (Gagne, 2015).

Por su parte, Los Zetas actualmente ejercen control territorial sobre el tráfico de cocaína en las cinco principales provincias de Guatemala - Petén, Huehuetenango, Quiché, Alta Verapaz y Zacapa- a través de la banda conocida como Los Lorenzanas en una ruta que surca el país desde la frontera con Honduras hasta el límite con México como puede apreciarse en la Figura 1. Además, otros cuatro municipios limítrofes con Honduras y con salida a la costa del Pacífico - Chiquimula, Jutiapa, Jalapa y Santa Rosa - fueron arrebatados por Los Zetas al grupo local dominante Los Leones, cuya dirigencia fue abatida por la organización narcotraficante mexicana. 


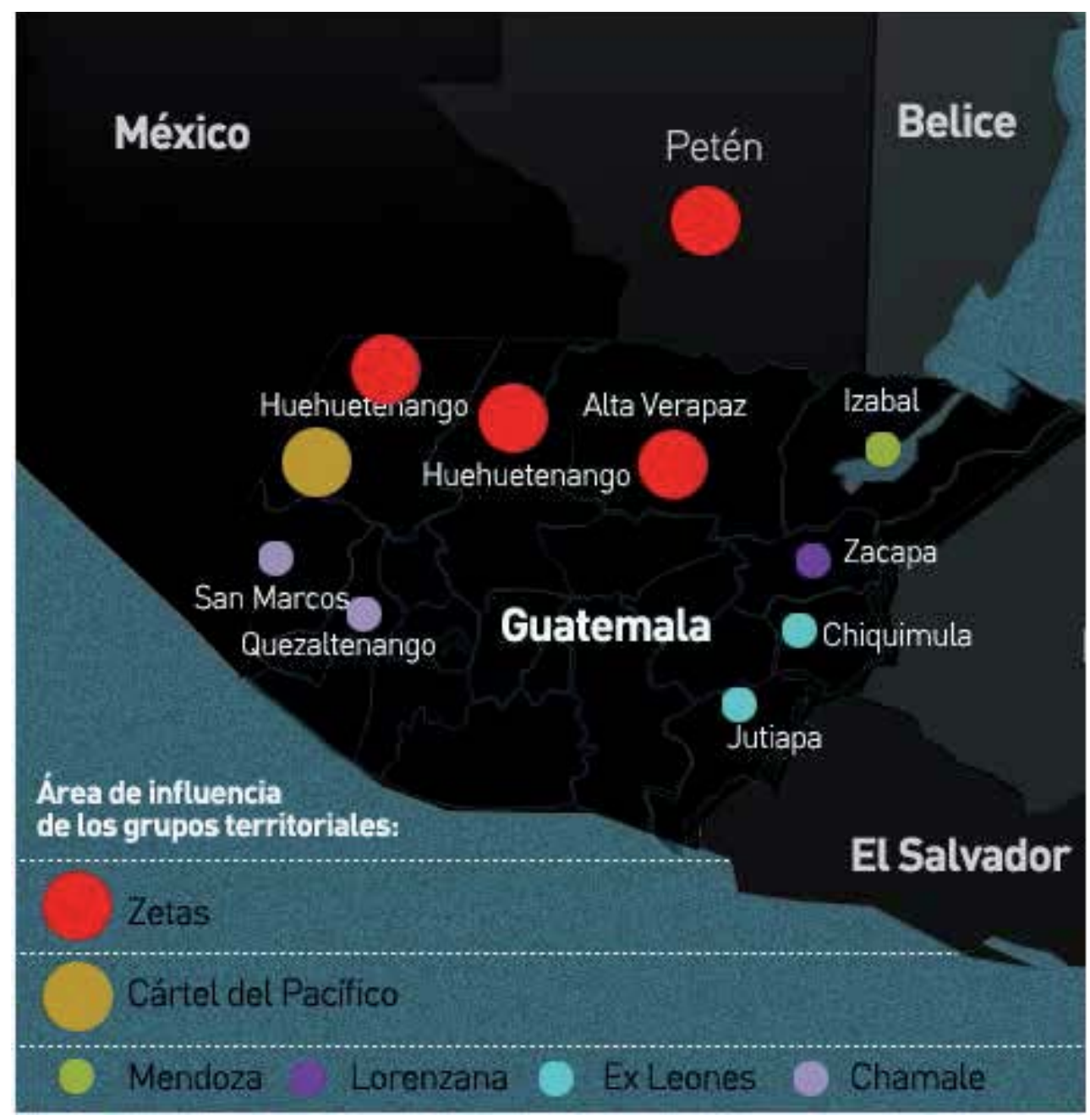

Figura 1: Área de influencia territorial Los Zetas y Cártel del Pacífico en Guatemala. Fuente: Extraído de Martínez (2 de junio 2013).

Mientras tanto, el Cártel del Pacífico posee el control de la provincia de San Marcos, fronteriza con México y en la que se encuentra uno de los principales puertos marítimos guatemaltecos, y domina también la provincia de Izábal — colindante con Honduras, Belice y con salida hacia el Golfo de México - y por el otro se encuentra cercado por las provincias bajo influencia de Los Zetas, grupo criminal con el que, además, el cártel liderado por El Chapo Guzmán mantiene una disputa por controlar Huehuetenango. 
Por lo tanto, la experiencia reciente demuestra que las victorias parciales de una nación determinada pueden convertirse en un fracaso para sus vecinos. Por esa razón, la subregión compuesta por México-Centroamérica, conectada a su vez con Estados Unidos, posee dinámicas de co-dependencia que obligan a pensar las soluciones a su dilema de seguridad en términos transnacionales (Garzón, 2013). De esa manera, si la diáspora criminal constituye una consecuencia directa - aunque no deseada - de la alta presión institucional ejercida en determinados países como México, los Estados limítrofes tendrían que trabajar coordinadamente a objeto de contrarrestar la expansión de las redes criminales mediante el desarrollo de mecanismos destinados a contener el efecto cucaracha. De lo contrario el éxito de un país específico podría verse seriamente comprometido por las acciones del mismo grupo criminal pero esta vez funcionando desde un territorio aledaño - como Los Zetas en Guatemala-.

\section{Conclusiones ¿Por qué funcionó contra Al Qaeda y no contra el narco?}

El hecho de que los arrestos o abatimientos de capos hayan generado brotes de violencia no implica necesariamente que hubiera sido preferible no realizarlos. Sin embargo, previamente a la puesta en marcha de una estrategia de seguridad como HVT es esencial revisar las experiencias similares y conocer las particularidades específicas del contexto. De ese modo, entre más antecedentes se recopilen y procesen, menos serán los efectos no deseados que se produzcan.

La experiencia mexicana permite extraer las siguientes lecciones sobre los criterios a considerar cuando se aplica una política de decapitación contra organizaciones criminales:

1. Los parámetros empleados para confeccionar la lista de objetivos de alto valor deben ser absolutamente explicitados y ajustarse al comportamiento de los miembros. Lo cual permite a las autoridades regular la conducta de los grupos criminales y focalizar sus esfuerzos en castigar a los individuos u organizaciones más letales. Esto quiere decir que el orden de prelación debe de estar determinado no por la prominencia relativa o tamaño de la organización, sino por la intensidad en el uso de la violencia. Mientras más violento sea un grupo criminal -definido, por ejemplo, mediante su participación en masacres- 
más recursos deben dedicarse a la captura de sus líderes (Hope, 2011). Pero, si se presenta la oportunidad de capturar algún líder criminal de alta jerarquía durante un operativo - aunque éste no figure en las primeras posiciones del ranking - igualmente debe aprovecharse.

2. La aprehensión del cabecilla siempre debe priorizarse sobre su deceso pues el detenido puede aportar información de inteligencia valiosa sobre la localización de otros objetivos o centros de operación. Además, en términos disuasivos, es más potente la imagen de un capo ante tribunales que un cadáver irreconocible, esto reviste particular importancia considerando la marcada tendencia a fabricar teorías de la conspiración que existe en México. Sin embargo, es recomendable que en algunos casos la captura de un líder sea proseguida de manera casi inmediata por su extradición pues existen personajes que, por su perfil o peligrosidad, son muy complejos de encerrar de manera segura en una prisión nacional -la huída de El Chapo Guzmán desde El Altiplano ilustra muy bien el problema penitenciario en el país-.

3. La excesiva dependencia de situaciones azarosas - acusaciones sobre favoritismo por una organización criminal en particular o la instrumentalización de la figura de testigos protegidos - demuestra que el gobierno busca generar un impacto mediático mediante el golpe. Como argumenta Pérez Caballero (2014) si se mira en perspectiva, es válido preguntarse cuántas generaciones de narcotraficantes han sido decapitadas en México, o sea, la estrategia HVT sí funciona pero corre el peligro de repetirse dado que instaura marcos e indicadores de evaluación erróneos. En consecuencia, la estrategia de supresión de líderes de alta jerarquía no debe concebirse como un fin en sí mismo ni debe evaluarse de manera aislada del fenómeno general. Ante todo se debe considerar que el éxito o fracaso debe medirse a partir de objetivos que impacten en el nivel de seguridad de la población como la disminución de los delitos de mayor connotación social o el flujo de drogas.

4. Tras la captura de un capo, las fuerzas de seguridad deberían desplegarse en su zona de influencia, a manera de prevenir que el vacío generado sea ocupado por otra organización criminal, lo cual podría disparar los niveles de violencia. No obstante, esa ocupación territorial debe llevarla a cabo también las agencias de desarrollo social pues como señala los carteles operan como constructores 
competitivos de Estado en aquellas áreas donde operan. En suma, la estrategia del gobierno federal no fue del todo equívoca, el error estuvo en cómo se concibió y llevó a cabo. Si se hubiera ejecutado de forma adecuada, la desactivación de blancos prioritarios habría podido desarticular estructuras de grupos violento definitivamente tal como ocurrió en Colombia hace 20 años o debilitarlos a tal punto que fueran incapaces de realizar operaciones de alto impacto - como sucede con Al Qaeda-(Arnaud, 2013).

5. El gobierno precisa conocer la dinámica interna de las organizaciones -el grado de disciplina y centralización del mando, la cadena sucesoria, los conflictos entre facciones, la proclividad a la violencia o la negociación entre sus integrantes- así como el escenario estratégico donde se desenvuelve - su número de competidores, sus recursos o capacidades y su presencia territorial-. En ese sentido, cabe resaltar que la estrategia de supresión de objetivos de alto valor suele funcionar mejor contra organizaciones jerárquicas que poseen un mando altamente centralizado - con férreas estructuras de control y disciplina-. Mientras que si es aplicada contra grupos criminales organizados horizontalmente - como redes flexibles-que realizan operaciones transfronterizas puede tener un efecto mínimo sobre su comportamiento. En el mejor de los casos, el resultado será su fragmentación en bandas de menor tamaño. Por ende, el resultado de la estrategia de decapitación dependerá, en gran parte, de cuan rígida sea la cadena de mando, constituyendo así en un factor crítico.

6. Deben tenerse en cuenta ciertas implicancias estratégicas, como realizar en paralelo a la captura de un capo, la detención de un número importante de lugartenientes y sicarios como una manera de: a) maximizar los efectos disuasivos del golpe $\mathrm{y} b$ ) neutralizar o mitigar los posibles agentes desestabilizadores como la generación de disputas sucesorias o ruptura de cuadros medios, vale decir, si se sabe que en la línea sucesoria existen integrantes violentos y moderados, debe procurarse que el vacío sea llenado por éstos últimos. Asimismo, si los miembros de menor jerarquía perciben que, una vez alcanzado cierto nivel de prominencia, son inmunes a la persecución porque su supresión ocasionaría efectos desestabilizadores, todos querrán cruzar ese umbral. A largo plazo, esa dinámica generaría aún más violencia que la evitada por el descabezamiento de la agrupación criminal, o sea, equivaldría a lo que en el submundo criminal se conoce como too big to fail (Hope, 2011). 
7. Concentrar los esfuerzos en la capa media de grupos delictivos tiende a ser más eficaz en términos de neutralización pues limita significativamente la capacidad regenerativa de liderazgo, disminuye más severamente su capacidad operativa, y puede permitir, posteriormente un procesamiento más eficaz de los principales jefes - siempre y cuando se logren acuerdos entre la fiscalía y los mandos medios golpeados a cambio de evidencia en contra de los objetivos de alto valor-. También tiene efectos sobre los niveles de violencia pues si la decapitación estimula un intento de anexión por otro grupo, es probable que sea menos violenta en razón de que la organización criminal cuya capa media ha sido eliminada tendrá una capacidad muy reducida para resistir la ocupación de su área de influencia y redes. Por ejemplo, la focalización en cuadros medios aplicada a los talibanes en Afganistán ha producido una nueva generación de comandantes de rango intermedio que es más violenta e intransigente y que abraza más firmemente la ideología yihadista global de Al Qaeda (FelbabBrown, 2013).

8. La capacidad de inteligencia requerida por los operativos focalizados en capas medias tiende a ser mucho mayor en comparación a HVT debido a que las unidades especializadas pueden tardarse varios años en desarrollar una panorámica completa de la organización que les permita identificar y monitorear a los individuos de dicha categoría. Además de preservar y aumentar la seguridad operacional a objeto de que información sensible no se filtre al grupo criminal que se pretende desarticular. En efecto, adoptar este enfoque representa un reto mayor en contextos marcados por la corrupción policial - como sucede en México- pues adicionalmente es preciso identificar los nexos entre la capa media y su red de protección al interior de la corporación. Siendo recomendable que su ejecución sea complementada por procesos de depuración institucional, rendición de cuentas-accountability - e imposición de sanciones disciplinarias. Incluso, en algunas ocasiones, este tipo de estrategia también contempla el desmantelamiento de la red criminal en su totalidad, incluyendo a funcionarios públicos corruptos, empresarios, operadores políticos, intermediarios financieros u otros miembros que la componen. Por esa razón, los operativos en contra de cuadros medios conllevan una compleja coordinación.

9. La inteligencia necesaria para neutralizar objetivos de alto valor puede ser proporcionada fácilmente por informantes externos o agentes encubiertos con amplia experiencia. En consecuencia, la estrategia de HVT implica operacio- 
nes más simples basadas en la inteligencia de señales - SIGINT, por sus siglas en inglés-, éste elemento ha reforzado aún más el atractivo de la estrategia HVT (Felbab-Brown, 2013). Así, la extraordinaria eficiencia en la obtención de información mediante la interceptación de señales en el campo de batalla y lenta adaptación de grupos criminales e insurgentes a este tipo de capacidades han fortalecido aún más la aplicación de estrategias de decapitación explícitamente orientadas al ataque del enemigo. La combinación de ambos aspectos se ha tornado altamente visible en la formulación de respuestas institucionales como la estrategia HVT que prescinden de una comprensión holística del teatro de operaciones-Afganistán-; establecimiento de un vínculo con la población local que facilite la obtención de inteligencia -Colombia-; y desarrollo de la capacidad de anticipar las acciones del enemigo - México- . Bajo esa lógica, los activos de inteligencia humana han sido subdesarrollados debido a la existencia de informantes proclives a proporcionar inteligencia contraproducente para los operativos. Por lo tanto, el proceso de recopilación de inteligencia a menudo posee un marcado sesgo militar en vez de realizar evaluaciones e interpretaciones más amplias de la inteligencia ya sea estratégica, política o socio-económica.

\section{Referencias}

Arnaud, R. (2013). ¿Qué tienen en común Al Qaeda, el cártel de Medellín y Los Zetas? Foreign Affairs Latinoamérica, 13 (14), 24-29.

Bagley, B. (2012). Drug trafficking and organized crime in the Americas: major trends in the Twenty-First Century. Washington D.C: Woodrow Wilson Center.

Corcoran, P. (16 de abril de 2015). Informe del gobierno de México señala que continúa la fragmentación de las organizaciones criminales. Insight Crime. Recuperado de http:// es.insightcrime.org/analisis/informe-gobierno-mexico-senala-continua-fragmentacion-organizaciones-criminales

Datos macro. (2015). Afganistán - homicidios intencionados 2015. Recuperado de http://www. datosmacro.com/demografia/homicidios/afganistan 
Felbab-Brown, V. (2013). Focused deterrence, selective targeting, drug trafficking and organised crime: Concepts and practicalities. Londres, Inglaterra: International Drug Policy Consortium (IDPC).

Gagne, D. (22 de julio de 2015). Los mejores escondites de El Chapo fuera de México están en países vecinos. Insight Crime. Recuperado de http://es.insightcrime.org/analisis/ mejores-escondites-el-chapo-extranjero-estan-paises-vecinos

Garzón, J. (2013). La diáspora criminal: la difusión transnacional del crimen organizado y cómo contener su expansión. En J. Garzón y E. Olson, La diáspora criminal: la difusión transnacional del crimen organizado y cómo contener su expansión (pp. 1-25). Washington, DC, Estados Unidos: Latin American Program Woodrow Wilson International Center for Scholars.

Guerrero, E. (1 de junio de 2011). La raíz de la violencia. Nexos. Recuperado de http://www. nexos.com.mx/?p=14318

. (1 de diciembre de 2012). La estrategia fallida. Nexos. Recuperado de http://www. nexos.com. $\mathrm{mx} / \mathrm{p}=15083$

Hope, A. (5 de diciembre de 2011). Decapitar o no decapitar. Recuperado de http://www. animalpolitico.com/blogueros-plata-o-plomo/2011/12/05/decapitar-o-no-decapitar/

International Crisis Group, (2013). El desafío de Peña Nieto: los cárteles criminales y el Estado de Derecho en México. Bruselas, Ginebra: International Crisis Group.

Kleiman, M. (2011). Surgical strikes in the drug wars. Foreign Affairs septiembre-octubre. Recuperado de https://www.foreignaffairs.com/articles/north-america/2011-09-01/ surgical-strikes-drug-wars

Lessing, B. (2014). The logic of violence in drug wars: cartel-state conflict in Mexico, Brazil and Colombia, Stantford, Center on Democracy Development and the Rule of Law Freeman Spogli Institute for International Studies. Recuperado de http://cddrl.fsi.stanford. edu/sites/default/files/145.Violent_Corruption_CDDRL_Working_Paper.pdf

Lohmulle, M. (12 de junio de 2015). Sólo quedan dos carteles de la droga en México: funcionario. Insight Crime. Recuperado de http://es.insightcrime.org/noticias-del-dia/soloquedan-dos-carteles-droga-mexico-funcionario 
López, X. y Meza, M. (15 de julio de 2015). "El Chapo" y los desaciertos de la estrategia de seguridad. CIDAC. Recuperado de http://cidac.org/el-chapo-y-los-desaciertos-de-laestrategia-de-seguridad/

Martínez, P. (2 de julio de 2013). Mapa centroamericano... de los cárteles mexicanos. Insight Crime. Recuperado de http://es.insightcrime.org/analisis/mapa-centroamericano-delos-carteles-mexicanos

Meyer, M. (2010). Obama y la Iniciativa Mérida: ¿El inicio de un cambio o continuidad de la fallida guerra contra las drogas? En R. Benítez Manaut (ed.), Crimen organizado e Iniciativa Mérida en las Relaciones México-Estados Unidos (pp. 31-68). Ciudad de México, México: CASEDE. Recuperado de http://www.casede.org/PublicacionesCasede/ CrimOrgeIniciativaMerida/cap3.pdf

-_-—. (2014). La policía en México. Washington, Estados Unidos: Oficina en Washington para Asuntos Latinoamericanos (WOLA).

Pérez Caballero, J. (2014). Antes y después de los titulares. Estrategia de militarización y táctica de decapitación en la "guerra contra el narcotráfico" en México. En M. Requena, VI Jornadas de Estudios de Seguridad (pp. 787- 820). Madrid, España: Instituto Universitario General Gutiérrez Mellado.

Pérez Correa, C., Silva, C. y Gutierrez, R. (1 de julio de 2015). Índice de letalidad. Menos enfrentamientos, más opacidad. Nexos. Recuperado de http://www.nexos.com.mx/?p=25468

Ramos, J. (2010). La Iniciativa Mérida en la frontera México-Estados Unidos. En R. Benítez Manaut (ed.), Crimen organizado e Iniciativa Mérida en las Relaciones México-Estados Unidos (pp. 31-68). Ciudad de México, México: CASEDE. de http://www.casede.org/ PublicacionesCasede/CrimOrgeIniciativaMerida/cap4.pdf

Ríos, V. (2012). Why did Mexico become so violent? A self-reinforcing violent equilibrium caused by competition and enforcement. Trends In Organized Crime, 16 (2), 138-155.

Rodríguez, A. (2010). La Iniciativa Mérida y la guerra contra las drogas. Pasado y presente. En R. Benítez Manaut (ed.), Crimen organizado e Iniciativa Mérida en las Relaciones México-Estados Unidos (pp. 31-68). Ciudad de México, México: CASEDE. Recuperado 22 septiembre 2015, a partir de http://www.casede.org/PublicacionesCasede/CrimOrgeIniciativaMerida/cap2.pdf 
Salcedo-Albarán, E. y Garay, L. (2012). ¿Por qué es más difícil desarticular las actuales redes criminales mexicanas que los carteles colombianos de los noventa? Análisis comparado a partir del concepto de resiliencia de redes sociales. Bogotá, Colombia: Scientific Vortex Foundation.

Servitja, X. (2012). El crimen organizado en México y el 'Triángulo Norte' durante el mandato de Felipe Calderón. Madrid, España: Instituto Español de Estudios Políticos y Estratégicos (IEEE).

Williams, P. (2010). El crimen organizado y la violencia en México una perspectiva comparativa. Istor: Revista de Historia Internacional, 11 (42), 15-40. 